\title{
Gerenciamento distrital e local do Protocolo de Toxoplasmose Congênita em Venda Nova: Pet GraduaSUS do Curso Gestão de Serviços de Saúde
}

\author{
Elizabeth Morbeck, Alexsandro Oliveira, Elkimen Noêmia, Kátia Ferreira Costa Campos, Keli \\ Bahia Felicíssimo Zocratto
}

\section{Resumo}

Introdução: A Política Nacional de Educação Permanente, instituída pela portaria GM/MS 1.996/2007, foram validados todos os princípios da educação permanente. Uma de suas estratégias é a aprendizagem pela construção de novos significados para os processos de trabalho com ações educacionais de trabalhadores em saúde fundamentadas no respeito às particularidades locoregionais, na lógica das necessidades de forma ascendente e coletiva, contemplando prioridades da gestão no monitoramento dos processos de aprimoramento e formação profissional. Em Belo Horizonte, a base territorial foi dividida em nove Distritos Sanitários, correspondendo às áreas administrativas da Prefeitura. No contexto descentralizado das políticas públicas, o nível de gestão regional conecta-se com os formuladores da gestão municipal e com seus executores no nível local. As sedes distritais são responsáveis diretos pela implementação, acompanhamento e avaliação da Atenção Primária à Saúde (APS), formada pelas áreas de abrangência dos Centros de Saúde (C.S.). Esta integração hierárquica dos níveis, central, distritais e locais, estabelece a estrutura organizacional da gestão do cuidado em saúde do município. Para enfrentar os desafios é necessário o desenvolvimento de competências e habilidades de gestão capazes de integrar diferentes saberes e tecnologias. Considera-se que a integração ensino-serviço é uma estratégia que pode proporcionar o desenvolvimento do aluno, e nesse sentido, o Programa de Educação pelo Trabalho em Saúde (PET Saúde), lançado em 2008, tem proporcionado aprendizado aos profissionais de saúde e acadêmicos, na forma de vivências, que contemplam as necessidades do SUS de educação pelo trabalho. O Programa se desenvolve por meio de integração interdisciplinar, parceria da Secretaria Municipal de Saúde (SMSA) de Belo Horizonte e a Universidade Federal de Minas Gerais (UFMG). As atividades de aprendizagem são coordenadas por tutores (professores universitários) que, em articulação com os preceptores (profissionais de áreas da rede municipal de saúde) e alunos de graduação. Objetivo: Qualificar os processos de integração ensino/serviço/comunidade a partir de um olhar específico da gestão sobre os indicadores Materno Infantil nos serviços da APS. Métodos: Trata-se de um relato de experiência da proposta desenvolvida pelo PETGraduaSUS do Curso de Gestão de Serviços de Saúde/UFMG desde maio de 2016 com previsão de término em fevereiro de 2018. A escolha da metodologia baseou-se no entendimento de que a mesma é capaz de propiciar e enaltecer a rotina dos serviços em saúde, possibilitando uma maior compreensão e construção de um pensamento lógico de resolutividade voltado para a gestão. Para o desenvolvimento dos projetos este estudo, utilizou-se a metodologia participativa como ferramenta que implica na coparticipação de diferentes atores sociais envolvidos no processo. Apresenta a perspectiva de conhecer o contexto no qual os atores se encontram inseridos, vinculados às situações que necessitam de intervenção. Na busca de alternativas, a reflexão e a ação, vinculadas a participação ativa dos sujeitos envolvidos produz ênfase na valorização do saber local que interage com o saber científico. As ações estabelecidas junto ao serviço estiveram vinculadas ao ciclo de vida Materno-Infantil do município de Belo Horizonte, e foram delineadas a partir de diagnósticos situacionais com posterior desenvolvimento de projetos de intervenção em cada campo estabelecido. Resultados: No Distrito de Venda Nova, além do levantamento dos indicadores materno-infantil, a toxoplasmose foi escolhida como tema de atuação, por assumir a maior relevância no período gestacional. A 
ISSN 2179-6750

Toxoplasmose é uma infecção parasitária causada por um protozoário, o Toxoplasma gondii; cujo reservatório natural é o gato. O homem é acidentalmente infectado, e a doença é adquirida pela ingestão de alimentos contendo cistos de Toxoplasma. Outra forma é pelas fezes de gatos, que eliminam grande quantidade de oocistos durante a infecção aguda. A infecção ocorre quando o parasita atinge o concepto por via transplacentária e a transmissão fetal acontece quando a mãe adquire-a durante a gestação. Assim, a infecção congênita não ocorre em mães que já tiveram infecção prévia, exceto quando ocorrer reativação por alguma forma de imunodepressão. O parasita se multiplica na placenta e ao ser transmitido para o feto pode causar lesões na retina e sistema nervoso central. As gestantes numa situação de primoinfecção, geralmente são assintomáticas e somente identificadas por exames sorológicos solicitados no acompanhamento do pré-natal. O tratamento é realizado no pré-natal, além da investigação das crianças suspeitas, após o nascimento. Os exames são realizados nos C.S. pela punção digital num papel filtro e, facilmente, transportados para o laboratório responsável pela análise, o Núcleo de Ações e Pesquisa em Apoio Diagnóstico da UFMG (NUPAD-UFMG). Os testes diagnósticos apresentam maior especificidade quando realizados até a $12^{\mathrm{a}}$ semana de gestação, realçando a importância de se iniciar o pré-natal logo no início da gravidez. A indicação é que esse teste deve ser repetido durante o acompanhamento, caso a gestante seja suscetível, isto é, apresente testes sorológicos (IgG e IgM) negativos. Os integrantes alocados na equipe PET - Venda Nova com o propósito de contribuir para o enriquecimento do processo de aprendizagem, optaram pelo estudo de caso como estratégia de investigação. O projeto aconteceu em fases, que foram distribuídas da seguinte forma: Fase I (Observacional) que consiste na inserção dos alunos nas UBS, com o objetivo de adquirirem vivências da organização da APS nos C.S., bem como os elementos que compõem sua estrutura, seus métodos gerenciais e suas práticas profissionais para a gestão e capacitação de pessoas.Por meio desta vivência, além de serem contextualizados e sensibilizados para compreender os processos realizados nos C.S, os alunos do curso de Gestão em Serviços de Saúde criaram um portfólio contendo registros textuais e não textuais da realidade encontrada, a fim de obterem minúcias sobre as características do espaço, seus processos de trabalho, estabelecimento de rotinas, entre outros. Na fase II ocorreram as Coletas e Tabulações vinculados à Toxoplasmose que consiste no acompanhamento de primeiras e segundas consultas de pré-natal realizadas pelas equipes, nas quais acontecem as abordagens dos profissionais com a gestante, a respeito da Toxoplasmose Congênita. Nesta fase, os alunos tabularam os dados em relação ao processo da consulta, com ênfase no protocolo, com auxílio da elaboração de gráficos e tabelas, fazendo posteriormente uma análise descritiva. Para o acompanhamento das demais consultas, os alunos recolheram dados no SIS Rede - SMS-BH, dos indicadores do Distrito de Venda Nova e no portal NUPAD - Triagem Pré-Natal. A fase III consiste no rastreamento do exame, a fim de detectar possíveis erros de administração do protocolo na saída e chegada do mesmo no CS e na esfera distrital. A fase IV aborda a elaboração de uma estratégia de melhoria dos índices materno-infantil de cunho gerencial, baseado na experiência vivenciada. Estas estratégias pensadas serão apresentadas formalmente para as gerências de cada unidade, que poderá utilizá-las como ferramentas para correção do problema. A fase $\mathrm{V}$ é a avaliação das medidas adotadas pelas gerências locais através da ferramenta de qualidade Ciclo PDCA e discussão com as gerências locais. Conclusões: Ações desenvolvidas apresentam foco na interdisciplinaridade e interprofissionalidade, na integração ensino/serviço/comunidade, na humanização do cuidado, na integralidade da assistência, no desenvolvimento das atividades que considerem a diversificação de cenários de práticas e redes colaborativas na formação para o SUS. O Pet Gradua SUS do Curso de Gestão de Serviços de Saúde, buscou identificar nas propostas de intervenção uma formação diferenciada para o trabalho no SUS, fortalecido pela prática e EPS.

Descritores: Educação, Educação Permanente, Políticas Públicas, Gestão em Serviços, indicadores básicos de saúde 